This is a postprint version of the following published document:

Serrano, B., Baselga, J., Esteban, I., Sesé, L. M.,

F. Piérola, I. (2003). Morphology of phase separated blends of poly(cyclohexyl methacrylate) with poly(vinyl acetate). Journal of Applied Polymer Science, 89 (5), pp. 1284-1290.

DOI: 10.1002/app.12239

(C) Wiley Periodicals, Inc., 2003 


\title{
Morphology of Phase Separated Blends of Poly(cyclohexyl methacrylate) with Poly(vinyl acetate)
}

\author{
B. Serrano, ${ }^{1}$ J. Baselga, ${ }^{1}$ I. Esteban, ${ }^{2}$ L. M. Sesé, ${ }^{2}$ I. F. Piérola ${ }^{2}$ \\ ${ }^{1}$ Instituto Tecnológico de Química y Materiales Álvaro Alonso Barba, Universidad Carlos III, 28911 Leganés, Spain \\ ${ }^{2}$ Departamento de Ciencias y Téchnicas Fisicoquímicas, Universidad a Distancia (UNED), 28040 Madrid, Spain
}

\begin{abstract}
:
Blends of poly(vinyl acetate) (PVAc) and poly(cyclohexyl methacrylate) (PCHMA) labeled by copoly-merization with 4-methacryloylamine-4 $\square$-nitrostilbene (Sb), with (1-pyrenylmethyl)methacrylate (Py) or with 3-(methacryloylamine)propyl- $N$-carbazole (Cbz), were prepared by casting dilute solutions in tetrahydrofurane (THF) or chloroform onto silanized glass plates. The resulting films were studied by epifluorescence microscopy, microfluorescence spectroscopy, DSC and optical microscopy. Epifluorescence micrography probes the chemical composition of the different regions in phase separated blends, with black areas corresponding to PVAc rich regions and colored areas corresponding to labeled PCHMA rich regions. The technique also visualizes primary and secondary morphologies, which depend on the composition of the polymer blend and on the casting solvent. Mixtures containing $80 \mathrm{wt} \%$ PCHMA show, in general, a bicontinuous primary morphology suggesting a spinodal demixing mechanism. Solvent effects are particularly relevant for $50 \%$ and $20 \%$ PCHMA samples showing morphologies composed of PCHMA rich domains, in a matrix of solvent-dependent compositions. Samples cast from chloroform are more homogeneous and the matrix is always highly fluorescent. In contrast, the domains of samples cast from THF are heterogeneous in size and shape and the matrix is non-fluorescent, being thus formed by nearly pure PVAc. Small voids are formed in the polymer-air interface. They are submicrometric for THF cast films and disappear with annealing at $122^{\circ} \mathrm{C}$. For chloroform cast samples they are much less frequent and appear well ordered, forming a mostly hexatic two dimensional network.
\end{abstract}

Key words: fluorescence; imaging; blends

\section{INTRODUCTION}

Polymer blends ${ }^{1}$ may have properties intermediate to those of monocomponent systems, or they may have new and improved properties. This is one of the reasons they have been a subject of research for a long time. Originally, the focus of most studies was finding polymer pairs able to form compatible blends by themselves or with a suitable compatibilizer. More recently, the emphasis has shifted to incompatible blends, in search of the mechanism of phase separation, of improving mechanical behavior for specific morphologies, or of compatibilizers able to give good adhesion between phases and to stabilize the multiphasic morphology (see ${ }^{2}$ Steiner and Klein, 1994; ${ }^{3}$ Kudva et. al, 1998; and references therein).

Blends of acrylic polymers with poly(vinyl acetate) (PVAc) have potential applications as coatings when they are compatible, but it is well known that both solvent $^{4-6}$ and method of preparation ${ }^{7-9}$ play an important role in the morphology of such polymer blends. In this work, poly(cyclohexyl methacrylate)

Correspondence to: J. Baselga (jbaselga@ing.uc3m.es) or I. F. Piérola (ipierola@ccia.uned.es).
(PCHMA) was chosen as an acrylic polymer, and solvent effects on the morphology of PCHMA-PVAc blends of different compositions, prepared by casting, were studied.

Very little is known about the compatibility of PCHMA with vinyl polymers. It forms transparent and apparently homogeneous blends with poly(4methylstyrene) and with polystyrene, ${ }^{10-12}$ judging from thermal and rheological properties. Such blends show lower critical solution temperatures (LCST) at 245 and $220^{\circ} \mathrm{C}$ respectively, with irreversible phase separation. ${ }^{10,11}$ Blends of PCHMA with PVAc show phase separation in films cast at room temperature. ${ }^{6}$ Other acrylic polymers, such as poly(methyl methacrylate) (PMMA) are also incompatible with PVAc, ${ }^{4,13,14}$ and their developed morphology depends on the method of preparation.

The criteria for judging polymer compatibility depend on the property considered. Mixing at the molecular level represents the perfect compatibility, but it is not common. More often, mixing occurs on a coarser scale, and at least two phases with different compositions may be observed. Epifluorescence microscopy (EFM) with imaging detection and microfluorescence spectroscopy (MFS) are convenient techniques in studying polymer compatibility. Both have been successfully employed to characterize mixtures of PVAc 
TABLE I

Characteristics of Polymer Samples

\begin{tabular}{lccccc}
\hline & $\begin{array}{c}\text { Molecular weight } \\
\left(M_{w} \times 10^{-3}\right)\end{array}$ & $\begin{array}{c}\text { Polydispersity } \\
(\mathrm{r})\left(M_{w} / M_{n}\right)\end{array}$ & $\begin{array}{c}\text { Molar extinction } \\
\text { coefficient }{ }^{\mathrm{b}}(\varepsilon) \\
\left(\mathrm{M}^{-1} \mathrm{~cm}^{-1}\right)\end{array}$ & $\begin{array}{c}\text { Chromophore } \\
\text { mole fraction } \\
(\mathrm{Fc})(\% \mathrm{~mol})\end{array}$ & $\begin{array}{c}\text { Glass transition } \\
\text { temperature } \\
\left(T_{g}\right)\left({ }^{\circ} \mathrm{C}\right)\end{array}$ \\
\hline PVAc & 90 & - & - & 0 & 40 \\
PCHMA(Py) & 150 & 10.8 & $45.6 \times 10^{3}(344 \mathrm{~nm})$ & 0.20 & 82 \\
PCHMA(Sb) & 104 & 8.8 & $14.6 \times 10^{3}(366 \mathrm{~nm})$ & 0.49 & 72 \\
PCHMA(Cbz) & 102 & 8.6 & $5.10 \times 10^{3}(345 \mathrm{~nm})$ & 0.20 & 74 \\
\hline
\end{tabular}

${ }^{a}$ Average molecular weight and polydispersity were determined by SEC.

$\mathrm{b}$ The molar extinction coefficient of the chromophore $(\varepsilon)$ is given for the maximum absorption wavelength.

and poly(vinyl alcohol) with dissolved fluorescent probes. ${ }^{15-18}$ Some other more sophisticated microscopic fluorescence techniques ${ }^{19-21}$ have also been employed to analyze the morphology of heterogeneous films. Imaging techniques have been extensively developed and applied to study polymer systems in the last five years.

\section{EXPERIMENTAL}

4-Methacryloylamine-4'-nitrostilbene $(\mathrm{Sb})$ and 3-(methacryloylamine)propyl- $\mathrm{N}$-carbazole (Cbz) were synthesized as previously reported. ${ }^{6,22,23}$ (1-Pyrenylmethyl) methacrylate (Py) (Scheme I) was supplied by Polysciences (Eppelheim, Germany) and used as received. Poly(cyclohexyl methacrylate) (PCHMA) labeled with $\mathrm{Sb}$, Py or $\mathrm{Cbz}$ was obtained by radical copolymerization of cyclohexyl methacrylate and the corresponding methacrylate bearing the desired chromophore. ${ }^{6}$ Poly(vinyl acetate) (PVAc) with molecular weight $9 \times 10^{4}$, was purchased from Polysciences and used without any further purification.

Table I summarizes the characteristics of the samples employed in this work. The chromophore mole fraction in the copolymer $(\mathrm{Fc})$ was determined by UV/VIS spectrophotometry (Perkin Elmer Lambda 4). Extinction coefficients were determined by calibration with THF solutions of the labeling comonomer and are included in Table I. Polymer molecular weights were determined by SEC (Shimadzu LC-9A) in THF at $30^{\circ} \mathrm{C}$, with standards of poly(methyl methacrylate) purchased from Polysciences. The polydispersity index of PCHMA samples was very high in every case (Table I) and the chromatograms of PCHMA(Sb) and $\mathrm{PCH}-$ $\mathrm{MA}(\mathrm{Cbz})$ were superimposable.

Solutions of PVAc and labeled PCHMA in THF or $\mathrm{Cl}_{3} \mathrm{CH}$, with $2 \mathrm{wt} \%$ total polymer concentration and different weight fractions of each polymer, were cast on glass plates at room temperature. Except when indicated, the glass plate was previously silanized with methyltrichlorosilane. Two casting procedures were employed: one in open air (quick evaporation) and the other in a solvent saturated atmosphere inside a closed vessel (slow evaporation). Quick evaporation was usually employed, except where indicated. The resulting films were circular, with diameters of about $1 \mathrm{~cm} 10 \mu \mathrm{m}$ thick. The border of the film, a crown of about $2 \mathrm{~mm}$, was excluded from observation.

After complete observation of the samples, they were annealed in a vacuum oven at $122^{\circ} \mathrm{C}$, for 4 hours, and measurements were repeated. The reproducibility of non-annealed samples was verified on three specimens of 50 / 50 PCHMA(Sb) / PVAc blends, cast from $\mathrm{Cl}_{3} \mathrm{CH}$ and from THF, on silanized and non-treated glass supports.

Several microscopes were employed: i) A Nikon Labophot provided with photographic camera and CCD videocamera plus videoprinter (all them from SONY) was employed for transmission optical microscopy (TOM) and epifluorescence microscopy (EFM) imaging observations. Objectives of 10X, 40X and 100X with NA of $0.25,0.65$ and 1.25 respectively, were employed. In EFM measurements, a $100 \mathrm{~W} \mathrm{Hg}$ arc lamp, filtered to transmit in the range of $330-380 \mathrm{~nm}$, was employed for excitation. The emission was separated from the excitation beam by a dichroic mirror for $\lambda_{\text {ex }}$ of less than $400 \mathrm{~nm}$ and a barrier filter for $\lambda_{\text {em }}$ of less than $420 \mathrm{~nm}$. ii) Microfluorescence-spectroscopy (MFS) measurements were performed with an inverted microscope Axiovert 100 TV (Carl Zeiss Jena) coupled by optical fiber to a monochromator from Acton. Details are given in reference 11. iii). A Nikon Epiphot microscope, coupled with CCD Sony Iris videocamera joined with Image-Pro Plus software from Media Cybernetics, was used to digitalize and analyze the images.

Measurements of the glass transition temperatures were performed ${ }^{24}$ in a Perkin Elmer DSC-7 with samples prepared by casting PCHMA(Py) / PVAc blends from THF and $\mathrm{Cl}_{3} \mathrm{CH}$ solutions. Samples were dried under vacuum at $50^{\circ} \mathrm{C}$ for 4 days and preheated in the calorimeter at $150^{\circ} \mathrm{C}$ for 10 minutes. No endotherm of solvent evaporation was observed in first run thermograms. First and second run glass transitions were coincident in $\pm 3^{\circ} \mathrm{C}$, except for one sample, as discussed in the text. Second and third run thermograms were identical. 


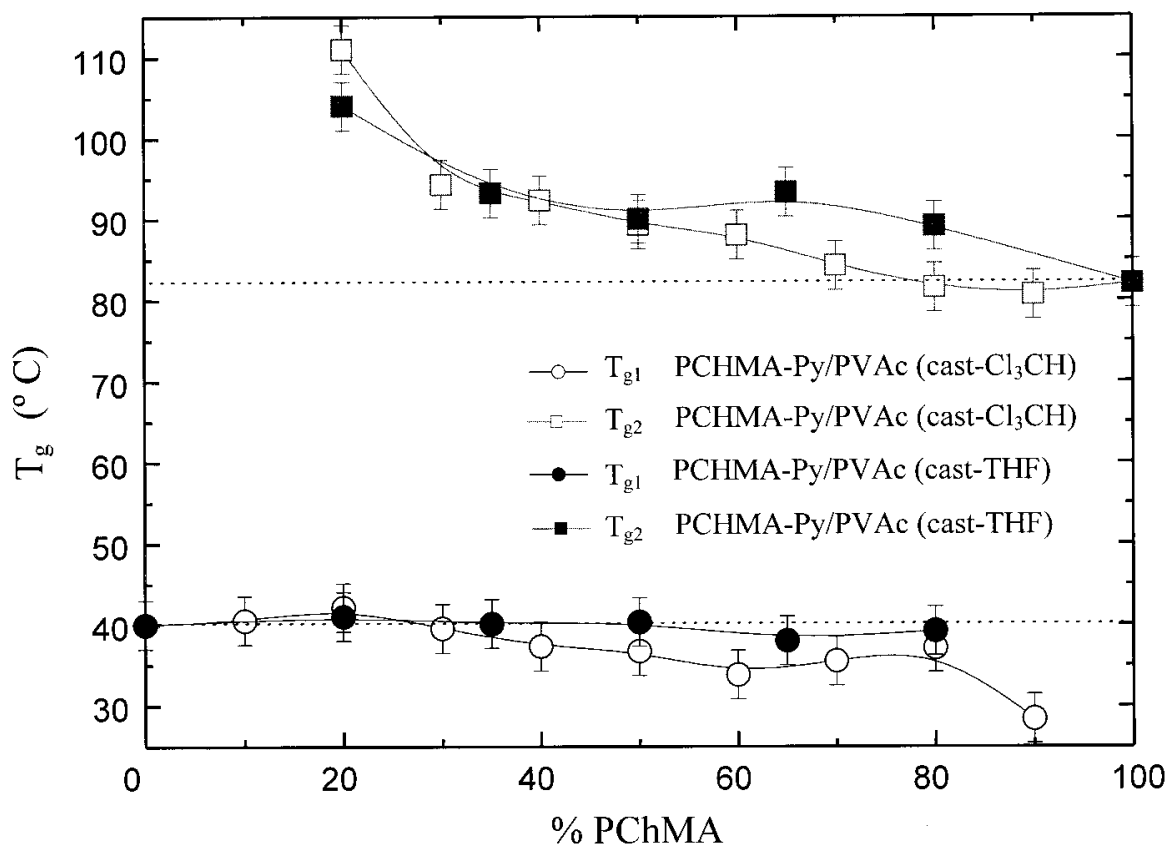

Figure 1 Second run glass transition temperatures of PCHMA(Py) / PVAc blends cast from $\mathrm{Cl}_{3} \mathrm{CH}(\bigcirc, \square)$ and THF $(\bullet, \mathbf{\square})$.

\section{RESULTS AND DISCUSSION}

\section{Glass transition behavior of blends}

The glass transition temperature $\left(T_{q}\right)$ of PCHMA(Py) / PVAc blends was measured for different compositions and two casting solvents ( $\mathrm{THF}$ and $\mathrm{Cl}_{3} \mathrm{CH}$ ) to assess its compatibility.

Figure 1 plots second run $T_{g}$ values as a function of the composition of blends cast in THF and $\mathrm{Cl}_{3} \mathrm{CH}$ at room temperature. Two $T_{g}$ values were observed in both first and second run DSC thermograms, except for two samples: i) The 80 / 20 PCHMA(Py) / PVAc blend cast from $\mathrm{Cl}_{3} \mathrm{CH}$ shows only one $T_{g}$ value of $61^{\circ} \mathrm{C}$ in the first run, but in the second run it shows two $T_{g}$ values (Fig. 1). ii) The 10\% PCHMA(Py) blend shows only one $T_{g}$ in both the first and the second run. Except for the first exception, the coincidence of first and second run $T_{g}$ values was in $\pm 3^{\circ} \mathrm{C}$.

Figure 1 shows that the system is incompatible for PCHMA compositions larger than $10 \%$. It also shows that: i) for THF cast blends, the $T_{g}$ of PVAc blends is essentially unmodified from that of the pure state, whereas for $\mathrm{Cl}_{3} \mathrm{CH}$ cast blends the $T_{g}$ is slightly smaller; and ii) the $T_{g}$ of PCHMA(Py) for both THF and $\mathrm{Cl}_{3} \mathrm{CH}$ cast solutions presents a systematic positive deviation with respect to the $T_{g}$ value in the pure state. For THF cast samples, a matrix of almost pure PVAc must be expected in phase separated blends.

$T_{g}$ values outside the range defined by the pure components can be explained as follows. Larger $T_{g}$ values than those of any of the pure homopolymers were previously observed for certain miscible blends, ${ }^{25,26}$ and it was ascrubed to polymer-polymer strong attractive interactions. Such interactions are not expected in the polymer pair studied here, but they could have been developed in the presence of a solvent, during casting. For example, it has been found that PMMA and PVAc show no specific interactions (according to the value of their interaction parameter ${ }^{27}$ ), but in solution attractive (in $\mathrm{Cl}_{3} \mathrm{CH}$ ) or repulsive (in THF) interactions develop. ${ }^{4,28}$ Extrapolating this qualitative behavior to the PCHMA-PVAc blends, it may be assumed that in ternary systems the polymerpolymer interaction is stronger than in the binary system in complete equilibrium. During casting, chain movements are progressively impeded and polymer conformations characteristic of concentrated solutions in THF or $\mathrm{Cl}_{3} \mathrm{CH}$ are frozen, inducing solvent dependent morphologies on cast films. Such non-equilibrium conformations of PCHMA would correspond to a larger rigidity (larger $T_{g}$ ) than pure PCHMA(Py), and only upon annealing for a sufficient time period could the solvent-independent equilibrium morphology be achieved. After the first heating and cooling by DSC, the sample is not yet at equilibrium, and thus second run $T_{g}$ values still reflect the influence of the casting solvent on the morphology of the polymer blend.

Concentrations of $80 \%$ and 50\% PCHMA / PVAc blends cast from THF are opalescent and under the optical microscope with crossed polarizers, they show Malta crosses indicative of stress birefringence, which suggests a compressed-state for PCHMA rich domains. This is in accordance with the larger $T_{g}$ measured for PCHMA in the blends and is supported by 

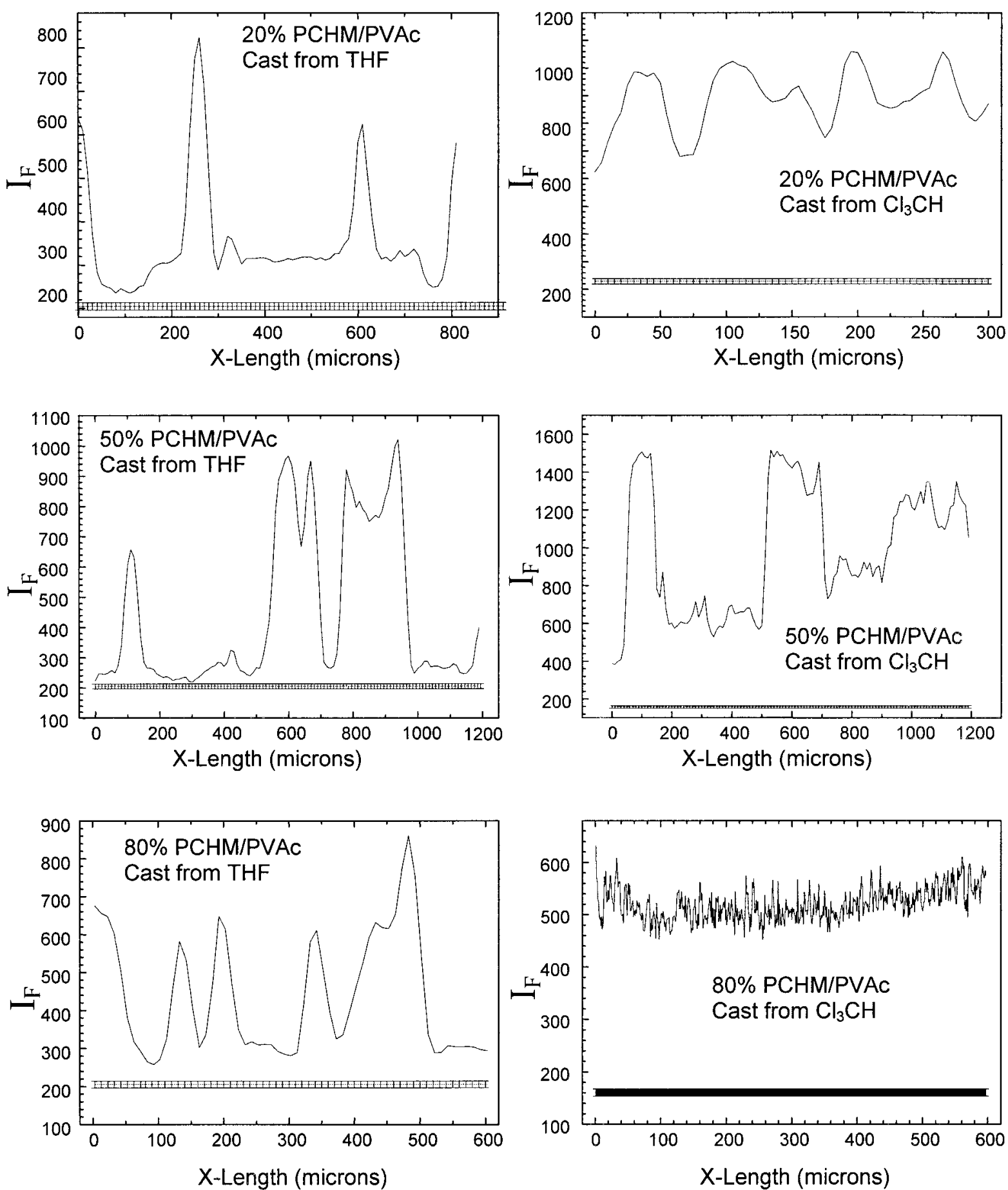

Figure 2 Fluorescence intensity $\left(\mathrm{I}_{\mathrm{F}}\right)$ of Py recorded at $394 \mathrm{~nm}$ as a function of the length of a straight line crossing the specimen for PCHMA(Py) / PVAc blends cast from THF (left column) and $\mathrm{Cl}_{3} \mathrm{CH}$, (right column).

previous results. ${ }^{29}$ When a highly flexible polymer allows a rigid polymer to form segregated microphases, it packs more compactly than in the homopolymer single phase and an increase in the $T_{g}$ of the rigid polymer is observed.

Explaining the behavior of blends with $T_{g}$ values lower than those of pure PVAc would require taking into account recently reported ${ }^{30}$ results which suggest that interfaces in phase separated PMMA-PS blends are enriched in chain ends. Since they have larger mobility than intermediate segments of the chain, a lower $T_{g}$ value than that of pure homopolymers should be expected for blends with large contribution of interfaces. A morphological study would reveal whether or not DSC results are in accordance with the microstructure of blends. 


\section{MFS and EFM results}

DSC results are in accordance with microfluorescence spectroscopy (MFS) and epifluorescence microscopy (EFM) observations for samples with $20 \%, 50 \%$ and $80 \%$ PCHMA(Py), cast from THF and $\mathrm{Cl}_{3} \mathrm{CH}$. MFS results are as follows. Figure 2 shows the fluorescence intensity of Py recorded at $394 \mathrm{~nm}$ as a function of the length shifted by the specimen under the microscope, in a straight line. The baseline is measured on the glass plate. For THF cast samples, several maxima corresponding to the section of fluorescent domains can be observed. Between maxima, the fluorescent intensity decreases to about zero; the regions between domains are formed by almost pure non-fluorescent PVAc. For $\mathrm{Cl}_{3} \mathrm{CH}$ cast samples, the intensity between maxima does not go to zero because the regions between fluorescent domains are also fluorescent. The sample with $80 \%$ PCHMA(Py) shows no maxima, as would a homogeneous blend, which accords with the single $T_{g}$ observed in the first DSC thermogram.

Epifluorescence micrographs also agree with glass transition temperatures and with MFS results. The 80 / 20 PCHMA / PVAc sample from $\mathrm{Cl}_{3} \mathrm{CH}$ is apparently homogeneous to the detection limit of the microscope, but, upon annealing in a vacuum oven at $122^{\circ} \mathrm{C}$ for 4 hours, phase separation is activated. This is suggested by the single $T_{g}$ value in the first run and the two $T_{g}$ values in the second run. Figure 3(a) shows the epifluorescence micrograph after annealing. Micrographs of THF cast samples show, for the three studied blend compositions, a totally dark (pure PVAc) base with dispersed blue regions (PCHMA(Py) [e.g. Fig. 3(b), 20\% PCHMA(Py) sample], whereas for $\mathrm{Cl}_{3} \mathrm{CH}$ cast samples the matrix is slightly fluorescent [e.g. Fig. 3(c), 50\% PCHMA(Py) sample] and therefore must be composed of a PCHMA(Py) / PVAc blend, enriched in the second component.

In all samples, primary and secondary morphologies were observed and the following are the most relevant results concerning changes of morphology with blend composition: i) $80 \%$ samples are bicontinuous, ii) $50 \%$ samples are approximate bimodal distributions of domains in a matrix of solvent dependent composition and iii) $20 \%$ samples also have solvent dependent morphologies, with small domains ordered in two dimensions.

\section{Bicontinuous morphologies of 80/20 PCHMA/PVAc mixtures}

Figure 4(a) shows a bicontinuous primary morphology representative of the behavior presented for 80 / 20 PCHMA(Sb, CBz) / PVAc cast from $\mathrm{Cl}_{3} \mathrm{CH}$ or THF. The obscured regions correspond to regions rich in non-emitting PVAc, whereas the brighter regions correspond to PCHMA rich compositions. Increasing

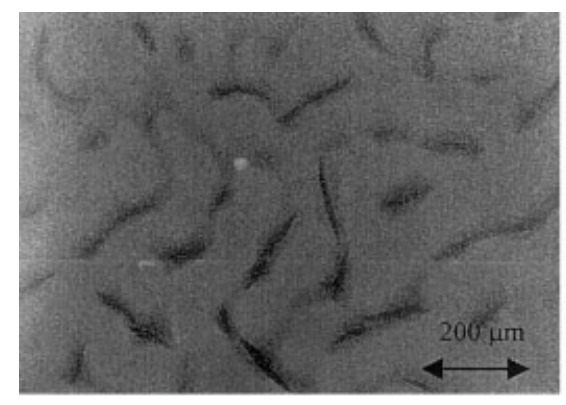

a)

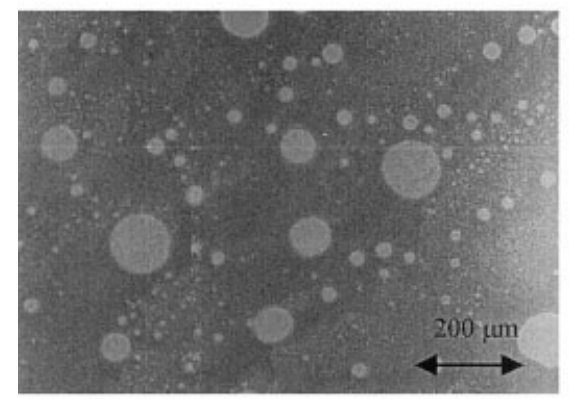

b)

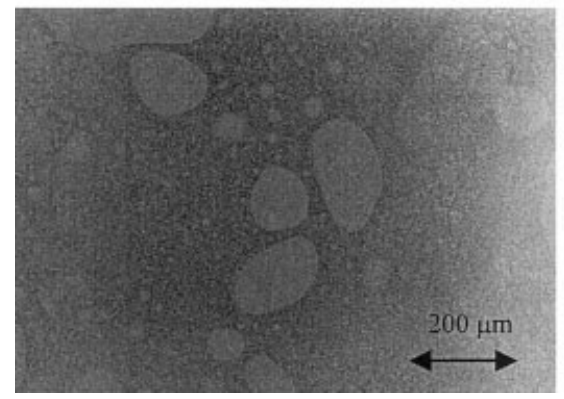

c)

Figure 3 EFM images of samples: (a) 80 / 20 PCHMA(Py) / PVAc cast from $\mathrm{Cl}_{3} \mathrm{CH}$ after annealing; (b) 20 / 80 PCHMA(Py) / PVAc cast from THF before annealing; (c) 50 / 50 PCHMA(Py) / PVAc cast from $\mathrm{Cl}_{3} \mathrm{CH}$, before annealing.

magnification [Fig. 4(b)] reveals a secondary phase-inphase morphology. Dark PVAc rich small domains are distributed within the bright PCHMA rich regions. This type of secondary morphology was previously observed $^{31,32}$ for systems reaching high viscosities during phase separation. This could also be the case for 80 / 20 PCHMA / PVAc samples; during solvent evaporation, highly concentrated solutions are generated whose viscosity may be large enough to inhibit the diffusion of small domains necessary for coalescence to occur.

Spinodal demixing of samples with compositions close to the critical point is the phase separation mechanism associated with bicontinuous primary morphologies, ${ }^{31,32}$ although earlier stages of phase separation should be observed to verify this mechanistic interpretation. The sample containing 80 / $20 \mathrm{PCHMA}(\mathrm{Sb}) /$ PVAc cast from THF, shows a primary droplet-inmatrix morphology with an underlying secondary in- 


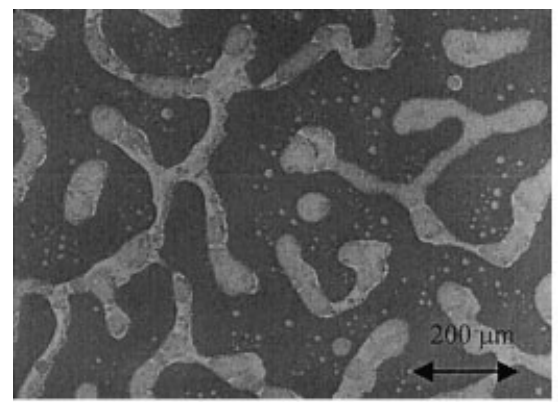

a)

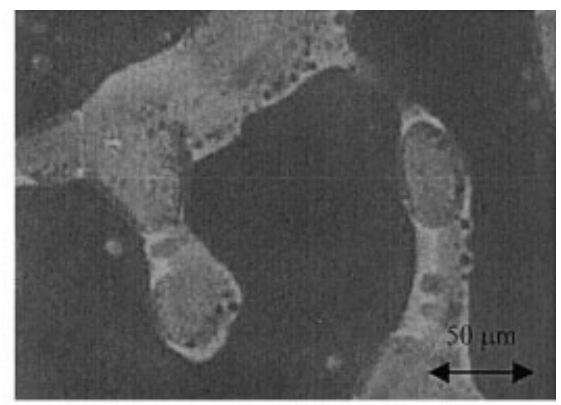

b)

Figure 4 EFM image of sample with ratio 80 / 20 PCHMA(Sb) / PVAc cast from $\mathrm{Cl}_{3} \mathrm{CH}$. The scale bar corresponds to (a) $200 \mu \mathrm{m}$ and (b) $50 \mu \mathrm{m}$.

terconnected-domains morphology. Upon annealing, an increase in the interconnectivity of PVAc rich domains in the secondary morphology is observed. There is no significant effect of annealing on the primary bicontinuous morphology in $\mathrm{Cl}_{3} \mathrm{CH}$ or THF-cast blends. Nevertheless, the annealing effect on the secondary morphology suggests that it was developed by viscosity inhibited diffusion, which is allowed by decreasing viscosity upon heating.

\section{Ordered small domains of 20/80 PCHMA/PVAc mixtures}

The largest solvent effect is found in 20 / 80 PCHMA / PVAc samples. Whereas samples cast from $\mathrm{Cl}_{3} \mathrm{CH}$ seem to be homogeneous unless observed with the largest magnification, samples cast from THF exhibit a well-defined domain-matrix morphology.

In apparently homogeneous samples, small PCHMA spherical domains with diameters about 5 $\mu \mathrm{m}$ are observed, and with lateral illumination it is demonstrated that they are voids in the polymer-air interface. Figure 5 shows the optical micrograph of a

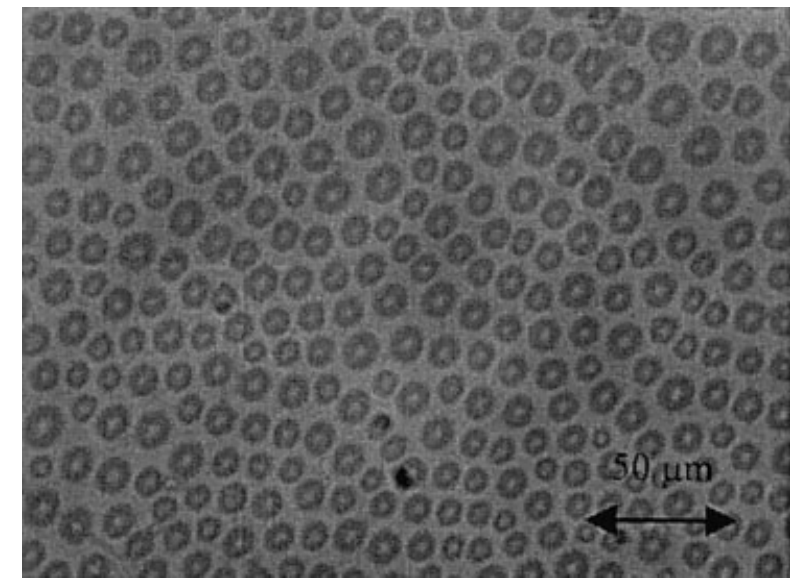

Figure 5 Optical micrograph of sample with ratio $20 / 80$ PCHMA(Py) / PVAc cast from $\mathrm{Cl}_{3} \mathrm{CH}$, with a two dimensional hexatic order. blend of 20 / 80 PCHMA(Py) / PVAc, cast from $\mathrm{Cl}_{3} \mathrm{CH}$. These small domains are aligned following curved parallel lines. Among the different tools for characterizing the order in the current samples, ${ }^{34}$ the Voronoi tessellation of the voids and the static structure factor $[S(\mathbf{k})]$ associated with the voids have been used. Both methods are commonly employed in the study of liquid and solid phases and are expected to yield valuable information here.

In order to resolve the foregoing issue and to identify the presence of ordered topologies, the static structure factor of the 'hole' centers has been determined. For the present purposes a convenient definition of $S(\mathbf{k})$ can be written as:

$$
\begin{aligned}
S(\mathbf{k})=\frac{1}{N^{2}}\left[\sum_{j=1}^{N} \exp \left(i \mathbf{k} \cdot \mathbf{R}_{j}\right)\right]^{2} & \\
& =\frac{1}{N^{2}}\left[N+2 \sum_{j>l} \cos \mathbf{k} \cdot\left(\mathbf{R}_{\mathbf{j}}-\mathbf{R}_{l}\right)\right]
\end{aligned}
$$

The latter formula comes from the theory of the elastic scattering of light by a sample ${ }^{35}$ having disregarded the usual statistical average over an ensemble. The vector $\mathbf{k}$ is the wave vector of the momentum transfer, and $\mathbf{R}_{\mathbf{j}}$ is the position vector of the scatterer $j$. The usefulness of $S(\mathbf{k})$ in the study of ordered or disordered phases lies in the fact that different $S(\mathbf{k})$ values correspond to different phases, and therefore different states of order or disorder ${ }^{36}$ : i) For perfect crystalline lattices there exists a set of maximizing $\mathbf{k}$ vectors that make $S(\mathbf{k})=1$; ii) For liquids, the maximum $S(\mathbf{k})$ value is 0.2 ; iii) For amorphous systems, 0.1 $\leq S(\mathbf{k}) \leq 0.3$; and iv) For partially crystalline phases, $0.3<S(\mathbf{k})<1$. The numerical results obtained here $(S(\mathbf{k})<0.1)$ indicate that the distributions of voids are highly disordered and of a liquid-like character. According to their maximum $S(\mathbf{k})$ values, the THF-cast blend $(S(\mathbf{k})<0.037)$ is less ordered than the $\mathrm{Cl}_{3} \mathrm{CH}$ cast blend $(S(\mathbf{k})<0.097)$. 


\section{CONCLUSIONS}

Fluorescence microscopy techniques allow chemical imaging in phase separated blends of labeled PCHMA with PVAc prepared by casting at room temperature. Primary and secondary morphologies can thus be observed. Samples of ratio 80 / 20 PCHMA / PVAc show bicontinuous primary morphologies, whereas samples of 50 / 50 and 20 / 80 composition are formed by droplets-in-matrix. This suggests LCST behavior with a minimum located below room temperature and significantly below $T_{g}$, in such a way that cooling produces compatible blends, but under these conditions, polymer mobility is not great enough to produce changes in morphology.

Primary morphology does not change significantly upon annealing except in one sample, the $80 / 20$ PCHMA(Py) / PVAc cast from chloroform, which changes from a single-phase aspect to the expected bicontinuous primary morphology. Annealing gives rise to coalescence of the smallest domains of the secondary morphology, as shown by films of any composition, particularly in a PVAc rich matrix. Viscosity of PVAc regions seems to be lower than that of PCHMA rich regions, since larger changes were produced by annealing in these regions.

Solvent effects on the secondary morphology and on the composition of domains may be related to the rate of solvent evaporation during casting. The two solvents here considered have similar physical properties, except for specific vaporization enthalpy, which for THF is twice that of $\mathrm{Cl}_{3} \mathrm{CH}^{33}$ Consequently, the time needed for evaporation of the same mass of both solvents under isothermal conditions must be about twice as long for THF than for $\mathrm{Cl}_{3} \mathrm{CH}$. Chloroform evaporates more quickly and freezes earlier stages of phase separation than THF, whereas blends cast from THF achieve a stage nearest equilibrium. It therefore seems that 20 / 80 PCHMA / PVAc samples demix initially, forming submicrometric domains in an ordered array. Samples of ratio 80 / 20 PCHMA / PVAc form bicontinous morphologies or form a single phase, depending on the molecular weight of PCHMA. For any blend, segregated domains are similar to the matrix in composition. At longer times, such domains become more abundant, more disordered, and have compositions closer to pure homopolymers.

This work was supported by DCI (Spain) and EU (BriteEuram) under grants BQU2000-0251 and BE-97-4672, respectively.

\section{References}

1. Paul, D. R.; Newman, S. Polymer Blends, Academic Press: New York, 1978.
2. Steiner, U.; Klein, J. Fetters, L. J. Phys Rev Lett 1994, 72, 1498.

3. Kudva, R. A.; Keskkula, H.; Paul, D. R. Polymer 1998, 39, 2447.

4. Crispim, E. F.; Rubira, A. F.; Muniz, E. C. Polymer 1999, 40, 5129.

5. Funaki, Y.; Kumano, K.; Nakao, T.; Jinnai, H.; Yoshida, H.; Kimishima, K.; Tsutsumi, K.; Hirokawa, Y.; Hashimoto, T. Polymer 1999, 40, 7147.

6. Serrano, B.; Baselga, J.; Bravo, J.; Mikes, F.; Esteban, I.; Sesé, L.; Piérola, I. F. J Fluorescence 2000, 10, 135.

7. Bastida, S.; Eguiazábal, J. I.; Nazábal, J. Eur Polym J 1999, 35, 1661.

8. García-Garduño, M. V.; Real, A.; Maciel, A. Cañetas, J.; Castaño, V. Int J Polym Mat 1998, 43, 333.

9. Kobashi, M.; Takeuchi, H. Macromolecules 1998, 31, 7273.

10. Jang, F. H.; Woo, E. M. Polymer 1999, 40, 2231.

11. Woo, E. M.; Jang, F. H. Polymer 1999, 40, 3803.

12. Friedrich, C.; Schwarzwalder, C.; Rieman, R. E. Polymer 1996, 37, 2499.

13. Friese, K.; Plast Kaut 1968, 5, 646.

14. Song, M.; Long, F. Eur Polym J 1991, 27, 983.

15. Granados, E. G.; González-Benito, J.; Baselga, J.; DibbernBrunelli, D.; Atvars, T. D. Z.; Esteban, I.; Piérola, I. F. J Appl Polym Sci 2001, 89, 949.

16. Atvars, T. D. Z.; Esteban, I.; Illera, B.; Serrano, B.; Vigil, M. R.; Piérola, I. F. J Lumin 1997, 72-74, 467.

17. Piérola, I. F.; Atvars, T. D. Z.; Salom, C.; Prolongo, M. G. In Polymer Materials Encyclopedia; Salamone, J. C., Ed.; CRC Press: Boca Raton, FL, 1996; Chapter 8, p 6362.

18. Dibbern-Brunelli, D.; Atvars, T. D. Z. J Appl Polym Sci 1995, 55, 889.

19. Li, L.; Chen, L.; Bruin, P.; Winnik, M. A.; Jao, T. C. Acta Polymerica 1996, 47, 407.

20. Jeuris, K.; Vanoppen, P.; Schryver, F. C.; Hofstraat, J. W.; Ven, L. G. J.; Velde, J. W. Macromolecules 1998, 31, 8579.

21. Vanoppen, P.; Hofkens, J.; Latterini, L.; Jeuris, K.; Faes, H.; Schryver, F. C.; Kerimo, J.; Barbara, P. F.; Rowan, A. E.; Nolte, R. J. M. In Applied Fluorescence in Chemistry, Biology and Medicine; Rettig, W., Strehmel, B., Schrader, S., Seifert, H., Eds.; Springer: Berlin, Ger., 1998.

22. Mikes, F.; Strop, P.; Kálal, J.; Makromol Chem 1974, 175, 2375.

23. Vyprachtický, D.; Pokorná, V.; Mikes, F. Macromol Chem Phys $1995,196,659$.

24. Serrano, B.; Levenfeld, B.; Bravo, J.; Baselga, J. Polym Eng Sci $1996,62,375$

25. Rodriguez-Parada, J. M.; Percec, V. Macromolecules 1986, $19,55$.

26. Rodríguez-Parada, J. M.; Percec, V. J Polym Sci, Polym Chem 1986, 24, 579.

27. O'Reilly, J. M.; Mosher, R. A. Macromolecules 1981, 14, 602.

28. Yang, H. Y.; Zhu, P. P.; Ren, F.; Wang, Y. Y.; Zhang, T. Eur Polym J 2000, 36, 21.

29. Bershtein, V. A.; Egorov, V. M. Differential Scanning Calorimetry of Polymers; Ellis Horwood: New York, NY, 1994; Chapter 4.

30. Soutar, I.; Swanson, L.; Cowie, J. M. G.; Barker, I. C.; Flint, N. J.; Conroy, M. J. Macromol Symp 1999, 141, 69.

31. Clarke, N.; McLeish, T. C. B.; Jenkins, S. D. Macromolecules 1995, 28, 4650.

32. Oyanguren, P. A.; Galante, M. J.; Andromaque, K.; Fontini, P. M.; Williams, R. J. J. Polymer 1999, 40, 5249.

33. Riddick, J. A.; Burger, W. B.; Sakano, T. K. Organic Solvents: Physical Properties and Methods of Purification; John Wiley \& Sons: Hoboken, NJ, 1986.

34. Allen, M. P.; Tildesley, D. Computer Simulations of Liquids; Clarendon: Oxford, Eng., 1989.

35. McQuarrie, D. A. Statistical Mechanics; Harper \& Row: New York, 1976

36. Melrose, J. R.; Singer, K. Molec Phys 1989, 39, 1203. 